\title{
KAJIAN PERBANDINGAN SUHU PANAS SIANG HARI TANPA NAUNGAN DAN DI BAWAH NAUNGAN TANAMAN RAMBAT MARKISAH (PASSIFLORA EDULIS)
}

\author{
Nurjannah Hamdani ${ }^{1}$, Marselly Dwiputri ${ }^{2}$ \\ ${ }^{1}$ Universitas Indraprasta PGRI, Program Studi Arsitektur \\ nurjannah.hamdani@gmail.com \\ ${ }^{2}$ Universitas Indraprasta PGRI, Program Studi Arsitektur \\ Marselly_dwiputri@yahoo.com
}

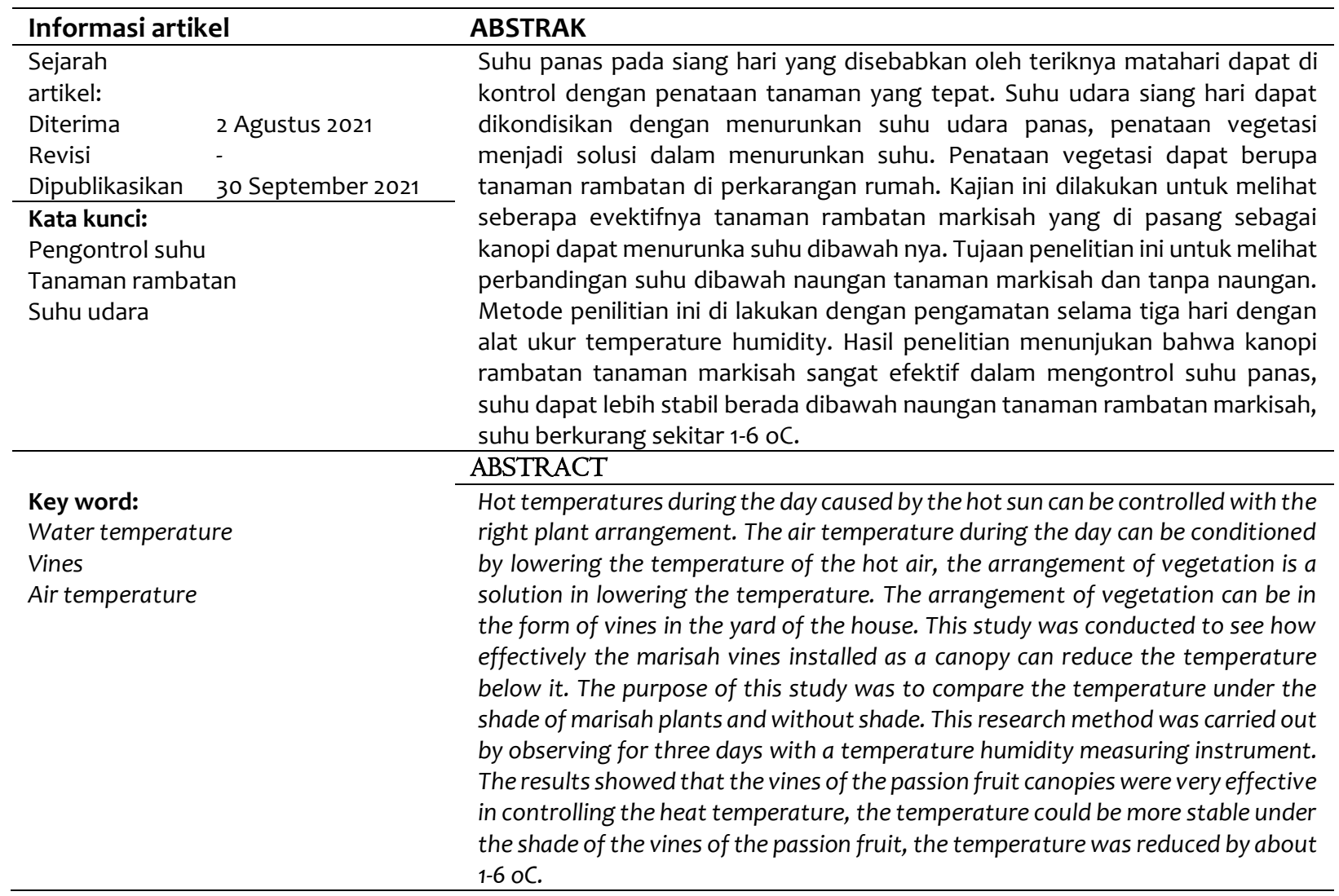

\section{PENDAHULUAN}

Peningkatan suhu udara panas pada siang hari terus terjadi salah satu faktornya adalah pengaruh globalisasi, pembangunan yang terus meningkan kesediaan lahan hijau yang berkurang sehingga pengaruh panas pada bumi menjadi meningkat. Menurut data dari Badan Meteorologi, Klimatologi dan Geofisika (2020), pengamatan pada 87 stasiun BMKG menunjukan suhu udara pada bulan Agustus periode 1981-2010 di indonesia sebesar 26.3 oC (dalam range normal 21.4 oC - 28.8 oC) dan suhu udara rata-rata bulan Agustus 2020 adalah sebesar 27.1 oC. Pengamatan dilakukan pada periode 1981-2020 terjadi anomali peningkatan suhu udara rata-rata 0.8 oC. BMKG juga menyatakan bahwa anomali suhu udara indonesia bulan Agustus 2020 ini merupakan anomali paling tinggi kedua sepanjang periode data pengamatan tersebut.

Suhu panas ini semakin meningkat jika lahan hijau terus berkurang. Penurunan suhu panas dapat dilakukan dengan adanya ruang terbuka hijau (RTH). Struktur vegetasi pohon adalah yang sangat evektif dalam memberikan kenyamanan pada lingkungan sekitar Ainy(2012). Menciptakan kenyamanan thermal untuk lingkungan rumah dapat dilakukan penataan perkarangan rumah berupa penanaman pohon ataupun membuat rambatan untuk tanman rambat yang dapat menjadi kanopi penghalang sinar matahari langsung. Adanya penataan tanaman rambat pada kanopi rumah dapat menurukan suhu, oleh karena itu untuk melihat kecendrungan penurunan suhu yang terjadi di bawah naungan tanaman rambat markisah dibutuhkan kajian penelitian. Tujuan penelitian ini yaitu: 1) 
mengkaji tingkat penurunan suhu dibawah naungan tanaman rambat markisah (Passiflora Edulis) dengan melakukan perbandingan suhu udara pada lokasi yang sama tanpa naungan.

\section{METODOLOGI}

Lokasi penelitian ini dilakukan pada salah satu rumah pada perumahan Aryatama regency 3, yang berlokasi di Jalan Haji Sulaiman, Kota depok, Jawa Barat, rumah yang dipilih rumah yang memiiki kanopi yang dibuat untuk merambat tanaman markisah (Gambar 1). Alat yang digunakan pada penelitian ini berupa kamera digital, alat tulis, temperature humidity meter dan komputer dengan software Microsoft Word dan Microsoft Excel. Bentuk kanopi yang disediakan untuk rambatan tanaman markisah berbentuk persegi panjang dengan lebar $3 \times 1.2$ meter dengan umur tanaman sekitar delapan bulan lihat gambar (1).
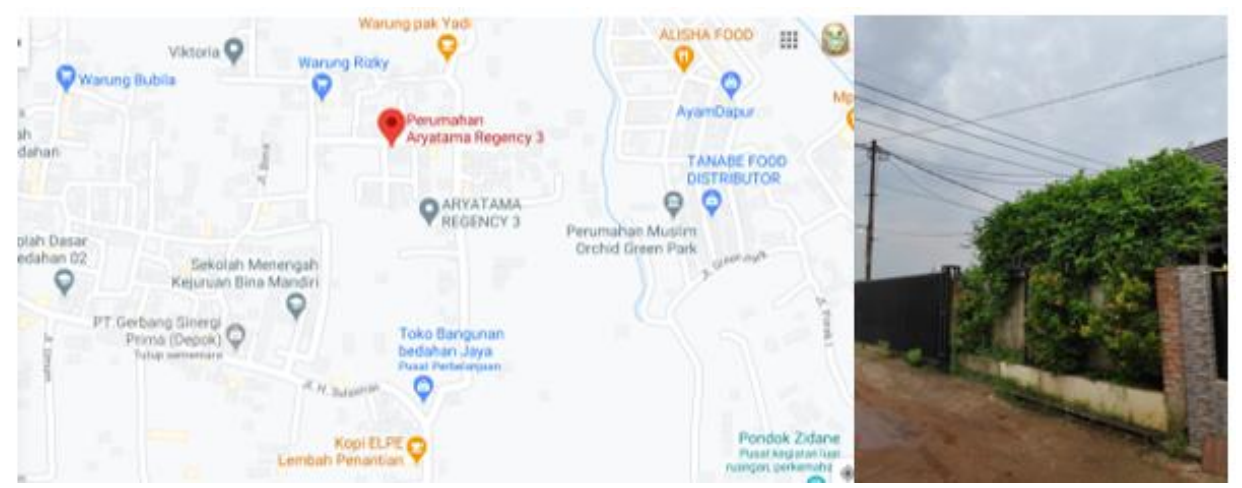

Gambar 1. Lokasi perumahan Aryatama Regency 3 dan kanopi rumah yang dikaji

Sumber: https://www.google.com/maps/place/Perumahan+Aryatama+Regency+3 dan data pribadi 2020

Penelitian dilakukan dengan metode pengamatan selama tiga hari, dari tanggal 8, 9 dan 12 pada bulan Agustus 2020. Menggunakan alat ukur suhu temperature humidity meter (lihat gambar 2). Pengumpulan data dilakukan pengamatan setiap jam selama delapan jam, dalam rentan waktu jam 10:00 sampai jam 18:00. Pengamatan suhu ini menggunakan dua alat ukur suhu yang satu ditempatkan dibawah naungan dan yang satu lagi ditempatkan tempat tanpa naungan. Setelah pengumpulan data dilakukan selama 3 hari, selanjutnya data dianalisis dengan melihat perbandingan suhu dibawah naungan dengan suhu tanpa naungan.
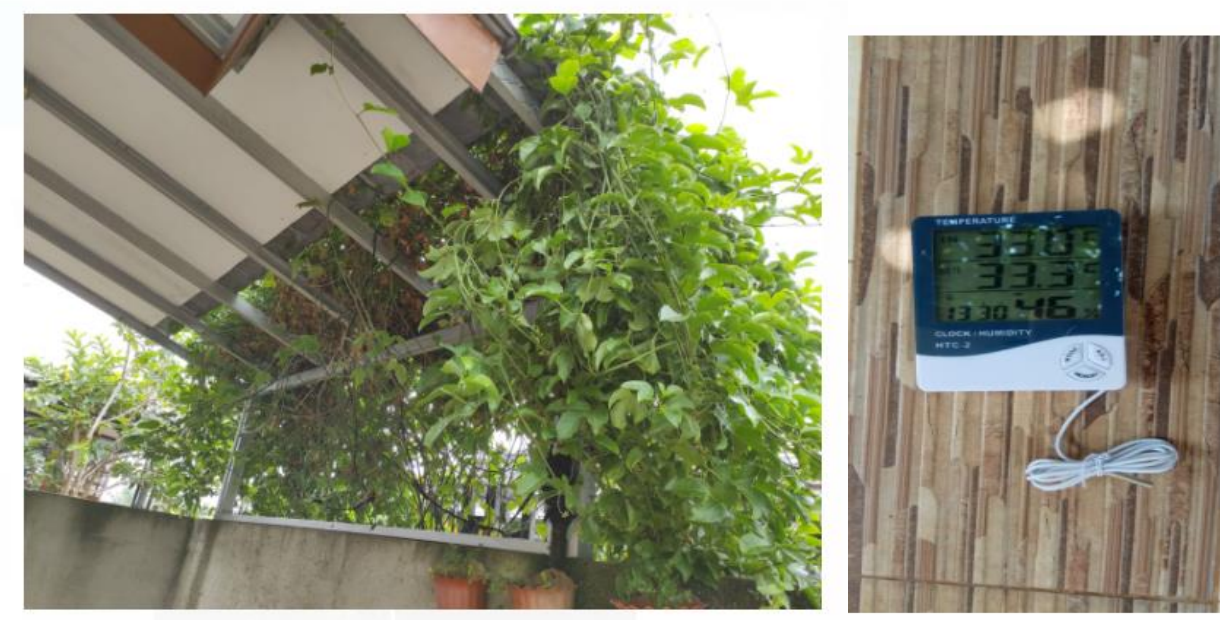

Gambar 2. Kanopi tanaman markisah dan alat ukur suhu (humidity meter) Sumber: Data pribadi 2020 


\section{HASIL DAN PEMBAHASAN}

Pengamatan suhu dilakukan pada satu lokasi dengan dua perlakuan, satu dilakukan dibawah naungan tanaman rambat markisah dan satu lagi dilakukan tanpa naungan. Data menunjukan pada penelitian ini suhu dibawah naungan cendurung lebih stabil dibandingkan yang tanpa naungan. Pengamatan pada tanggal 8 Agustus 2020 Ketika pengukuran suhu udara panas meningkat pada lokasi pengamatan tanpa naungan pada jam 11:00 menjadi $38.8^{\circ} \mathrm{C}$ dan jam $15: 00$ menjadi $38.6^{\circ} \mathrm{C}$, sedangkan pada lokasi pengamatan dibawah naungan rambatan pohon markisah tetap stabil berkisar suhu antarara $32{ }^{\circ} \mathrm{C}-32.5^{\circ} \mathrm{C}$. Pengamatan ini memperlihatkan perbandingan penurunan suhu sekitar $6.3^{\circ} \mathrm{C}-$ $6.8^{\circ} \mathrm{C}$. Pengamatan suhu dari jam 12.00 sampai 14.00 berkisar $37^{\circ} \mathrm{C}-33^{\circ} \mathrm{C}$ pada tanpa naungan ini pengaruh faktor cuaca pada hari pengamatan, namun perbedaan suhu juga turun pada pengamatan jam yang sama dibawah naungan yaitu berkisar $31.8^{\circ} \mathrm{C}-31^{\circ} \mathrm{C}$. Pengamatan pada jam ini menunjukan suhu turun sekitar $2.2^{\circ} \mathrm{C}-6.1^{\circ} \mathrm{C}$. Ketika pengukuran suhu udara pada jam 16:00-18:00 menunjukan suhu berkisar antara $33.8{ }^{\circ} \mathrm{C}-29.5^{\circ} \mathrm{C}$, hal ini tidak menunjukan penurunan suhu secara drastis pada perlakuan pengukuran suhu tanpa naungan dan dibawah naungan rambatan tanaman markisah. Penurunan suhu pada jam 16:00-18:00 dengan rasio $2.4{ }^{\circ} \mathrm{C}-0^{\circ} \mathrm{C}$ lihat gambar 3.

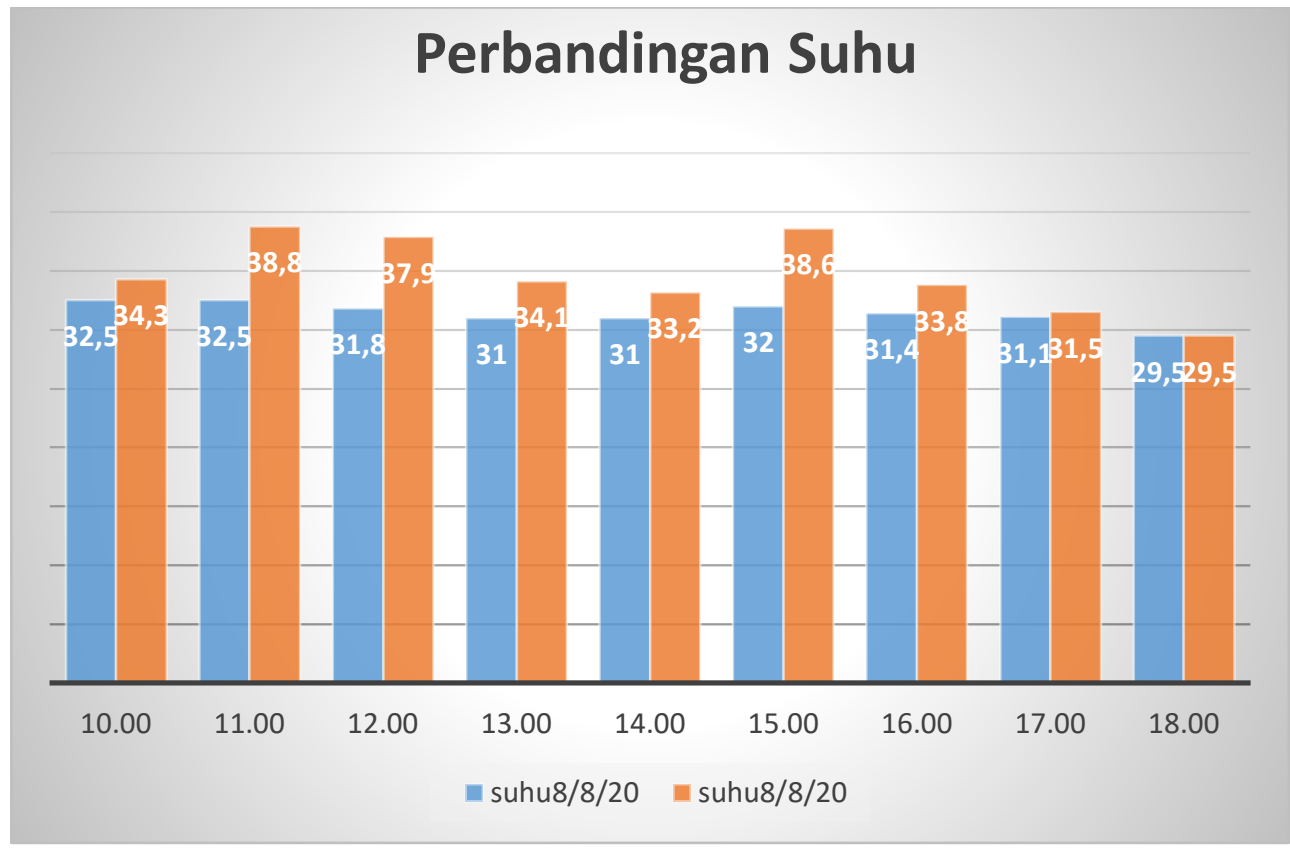

Gambar 3. Pembandingan suhu di bawah naungan dan tanpa naungan 8 Agustus 2020

Sumber: Analisis pribadi 2020

Hasil Pengamatan yang dilakukan pada hari kedua yaitu tanggal 9 Agustus 2020. Data pada hari ini menunjukan suhu panas meningkat pada jam 10.00 sekitar $35.5^{\circ} \mathrm{C}$ di lokasi tanpa naungan sedangkan pada lokasi yang memiliki naungan hanya bersuhu $31.7^{\circ} \mathrm{C}$, dari rasio perbandingan suhu pada jam 10.00, suhu berkurang sekitar $3.8^{\circ} \mathrm{C}$. Pengamatan tampa naungan pada jam 11.00 suhu meningkat menjadi $38^{\circ} \mathrm{C}$ sedangkan dibawah naungan suhu masih berkisar $32{ }^{\circ} \mathrm{C}$, rasio perbandingan ini memperlihatkan hasil penurunan sekitar $6{ }^{\circ} \mathrm{C}$ suhu lebih rendah dibawah naungan tanaman rambat markisah. Menunjukan bahwa penurunan suhu di bawah nanungan sekitar $3.8^{\circ} \mathrm{C}-6{ }^{\circ} \mathrm{C}$. lihat pada (Gambar 4). 


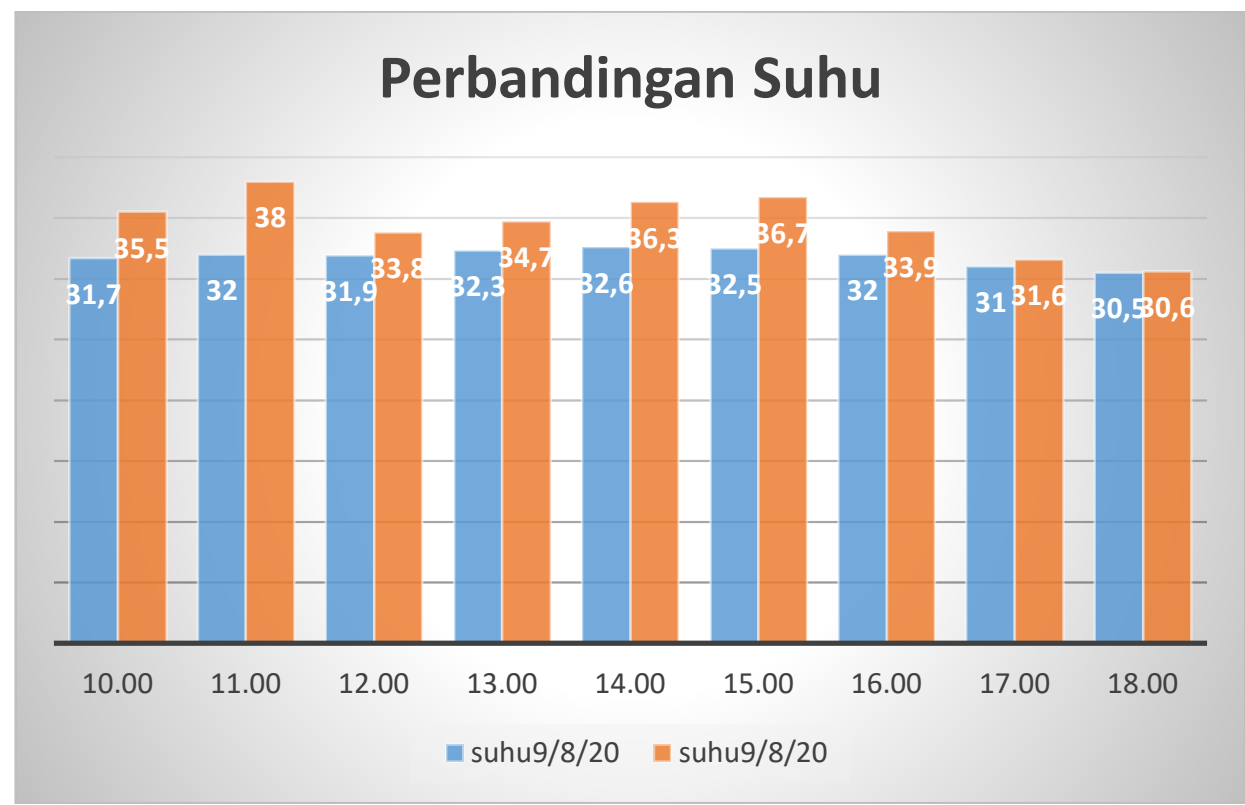

Gambar 4. Pembandingan suhu di bawah naungan dan tanpa naungan 9 Agustus 2020 Sumber: Analisis 2020

Hasil pengamatan hari ketiga pada tanggal 12 bulan Agustus 2020 menunjukan bahwa suhu jenderung meningkat dari jam 10.00 - jam 14.00 , suhu berkisar dari $36.1^{\circ} \mathrm{C}-41^{\circ} \mathrm{C}$ yang ditangkap oleh alat ukur suhu panas pada perlakuan tanpa naungan. Sedangkan pengamatan suhu pada jam 10.00 jam 14.00 juga ikut meningkat bekisar $31.3^{\circ} \mathrm{C}$ sampai dengan $34.9^{\circ} \mathrm{C}$. hal ini menunjukan peningkatan suhu di bawah naungan tergantung terik matahari pada saat pemantauan. Selisih suhu dari pemantaunan tempat nanungan dan tampa naunangan sekitar 3.9-5.6 ${ }^{\circ} \mathrm{C}$. lihat Gambar 5 .

\section{perbandingan suhu}

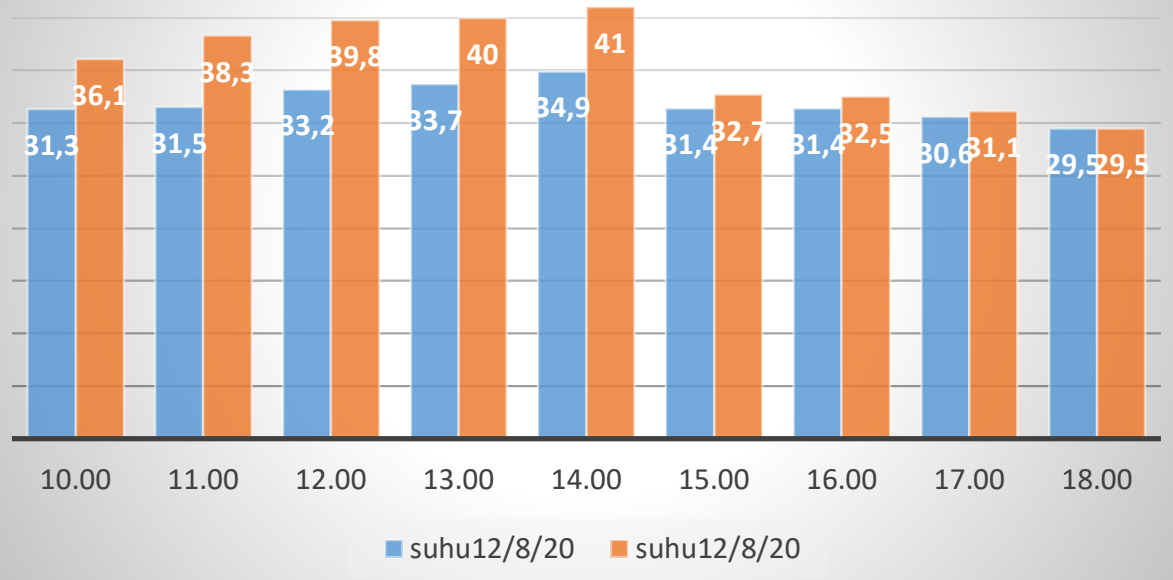

Gambar 5. Pembandingan suhu di bawah naungan dan tanpa naungan 12 Agustus 2020 Sumber: Analisis 2020

Berdasarkan hasil pengamatan selama tiga hari suhu panas pada siang hari menunjukan suhu tanpa naungan lebih panas sekitar $2.9^{\circ} \mathrm{C}-41^{\circ} \mathrm{C}$ suhu dibawah nanungan lebih rendah berkisar antara $2.9^{\circ} \mathrm{C}$ sampai dengan $34.9{ }^{\circ} \mathrm{C}$ dari data ini menunjukan bahwa tanaman dapat menurunkan suhu berkisar $1-6^{\circ} \mathrm{C}$. hal ini sesuai seperti yang di ungkapkan Femy (2014) tutupan kenopi pohon dapat mempengaruhi suhu yaitu semakin tinggi persentase tutupan vegetasi maka suhu udara lebih rendah. 


\section{PENUTUP}

Tanaman markisah yang merampat pada kanopi rumah dengan umur pohon berkisar 8 bulan dapat menurunkan suhu panas sekitar $2-6^{\circ} \mathrm{C}$. Suhu udara dibawah naungan lebih stabil berkisar dari $29^{\circ} \mathrm{C}-32{ }^{\circ} \mathrm{C}$, ini menunjukan bahwa penurunan suhu dibawah kanopi rambatan tanaman markisah sangat efektif dalam mengatur kenyamanan suhu udara pada ruang luar.

Sebaiknya untuk melihat kecendrungan penurunan suhu yang didapat dibawah naungan tanaman markisah dilakukan pada bulan Juli.

\section{DAFTAR PUSTAKA}

Ainy, Cheris Nurul. 2012. Pengaruh RTH Terhadap Iklim Mikro di Kawasan Kota Bogor Departemen Arsitektur Lanskap, Fakultas Pertanian, IPB

Femy, Budiarti T, Nasrullah N. 2014 pengaruh tata hijau terhadap suhu dan kelembaban relatif udara, pada balai besar pengembangan mekanisasi pertanian, serpong, jurnal lanskap indonesia vol 6 no 2.

https://www.bmkg.go.id/iklim/?p=ekstrem-perubahan-iklim diunduh pada 2 oktober 2020 https://www.google.com/maps/place/Perumahan+Aryatama+Regency+3 